E International

\title{
Planning and Designing Transport Systems to Ensure Safe Travel for Women
}

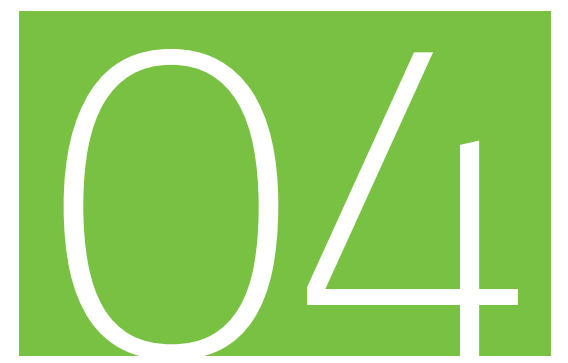

Discussion Paper 2014 04

Geetam Tiwari

Department of Civil Engineering, Indian Institute of Technology Delhi, India 


\title{
International Transport Forum
}

\section{Planning and designing transport systems to ensure safe travel for women}

Discussion Paper No. 2014-04

\author{
Geetam TIWARI
}

MoUD Chair Professor and Coordinator TRIPP Department of Civil Engineering Indian Institute of Technology Delhi

March 2014 
The International Transport Forum at the OECD is an intergovernmental organisation with 54 member countries. It acts as a strategic think-tank, with the objective of helping shape the transport policy agenda on a global level and ensuring that it contributes to economic growth, environmental protection, social inclusion and the preservation of human life and well-being. The International Transport Forum organises an annual summit of Ministers along with leading representatives from industry, civil society and academia.

The International Transport Forum was created under a Declaration issued by the Council of Ministers of the ECMT (European Conference of Ministers of Transport) at its Ministerial Session in May 2006 under the legal authority of the Protocol of the ECMT, signed in Brussels on 17 October 1953, and legal instruments of the OECD.

The Members of the Forum are: Albania, Armenia, Australia, Austria, Azerbaijan, Belarus, Belgium, Bosnia and Herzegovina, Bulgaria, Canada, Chile, People's Republic of China, Croatia, Czech Republic, Denmark, Estonia, Finland, France, Former Yugoslav Republic of Macedonia, Georgia, Germany, Greece, Hungary, Iceland, India, Ireland, Italy, Japan, Korea, Latvia, Liechtenstein, Lithuania, Luxembourg, Malta, Mexico, Republic of Moldova, Montenegro, the Netherlands, New Zealand, Norway, Poland, Portugal, Romania, Russian Federation, Serbia, Slovak Republic, Slovenia, Spain, Sweden, Switzerland, Turkey, Ukraine, United Kingdom and United States.

The International Transport Forum's Research Centre gathers statistics and conducts co-operative research programmes addressing all modes of transport. I ts findings are widely disseminated and support policymaking in Member countries as well as contributing to the annual summit.

\section{Discussion Papers}

The International Transport Forum's Discussion Paper Series makes economic research, commissioned or carried out at its Research Centre, available to researchers and practitioners. The aim is to contribute to the understanding of the transport sector and to provide inputs to transport policy design.

ITF Discussion Papers should not be reported as representing the official views of the ITF or of its member countries. The opinions expressed and arguments employed are those of the authors.

Discussion Papers describe preliminary results or research in progress by the author(s) and are published to stimulate discussion on a broad range of issues on which the ITF works. Comments on Discussion Papers are welcomed, and may be sent to: International Transport Forum/OECD, 2 rue André-Pascal, 75775 Paris Cedex 16, France.

For further information on the Discussion Papers and other JTRC activities, please email: itf.contact@oecd.org

The Discussion Papers can be downloaded from:

www. internationaltransportforum. org/jtrc/DiscussionPapers/jtrcpapers.html

The International Transport Forum's website is at: www. internationaltransportforum.org

This document and any map included herein are without prejudice to the status of or sovereignty over any territory, to the delimitation of international frontiers and boundaries and to the name of any territory, city or area. 


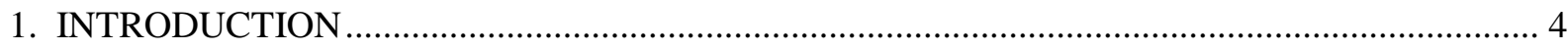

2. SUSTAINABLE TRANSPORT: ACCESS VS MOBILITY ................................................... 5

3. THE SHELTER-TRANSPORT-LIVELIHOOD LINK …..................................................... 7

4. TRAVEL PATTERN OF WOMEN IN INDIAN CITIES ................................................... 9

5. SAFETY PERCEPTIONS OF BICYCLE, PEDESTRIANS AND

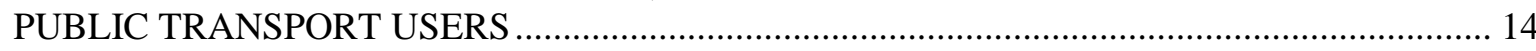

6. IMPACT OF CURRENT PLANNING PRACTICES AND URBAN ROAD DESIGNS.............. 15

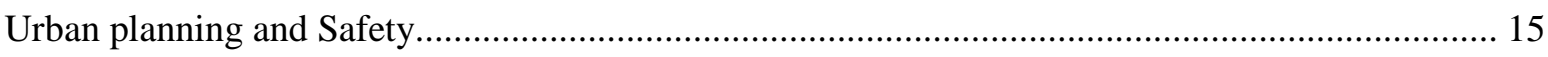

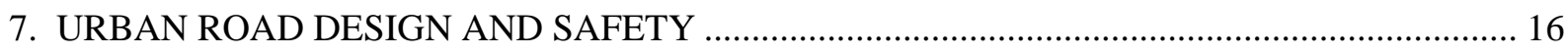

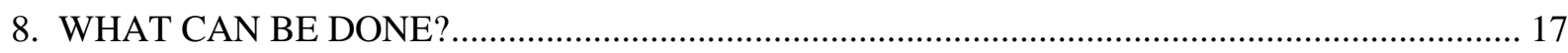




\section{INTRODUCTION}

Safe travel for all road users is a prerequisite for ensuring sustainable and inclusive cities. Providing safe transport system is an objective for sustainable transport, because risk of injuries and deaths from traffic crashes has become a major public health concern worldwide $(\mathrm{WHO}, 2011)^{1}$. At the same time safety of pedestrians, bicyclists and public transport users also has an impact on the choice of these modes. Risk to pedestrians, bicyclists and public transport users can be reduced by appropriate street designs and neighbourhood environment. Safer pedestrian and bicycle infrastructure results in increased use of these environment friendly modes (Tiwari \& Jain, 2012) ${ }^{2}$. Safe travel options for women in general and specifically low income women are important for addressing livelihood and poverty issues for a significant proportion of urban population in low income countries like India. In this paper we present data from two Indian cities- Vishakhapattanam( a city in south India with a population of 1.7 million persons) and Delhi the capital city of India having 16.4 million residents to compare the travel patterns of women and men. The household survey in Delhi focused on low income settlements since poverty adds another dimension to gender bias. The survey repeated after ten years shows that the travel patterns remain unchanged. Women travel shorter distances, are dependent on lower cost modes-walking and public transport and perform multi-purpose linked trips. In view of the sustainability requirements, lower mobility of women must be addressed by ensuring safe accessibility to employment opportunities by walking, bicycles and public transport. The paper concludes with possible interventions required to ensure safe and secure travel of women at land use planning level and street design level.

Worldwide men have higher risk of getting involved in traffic crashes than women (WHO). This is primarily attributed to lower presence of women on the road as compared to men, and differential risk taking behaviour observed in men and women. Safety and security of transport systems may have an impact on not only the choice of destination and mode used but the decision to travel itself.

Travel patterns of men and women are different has been reported by different researchers for a long time. Travel patterns of men and women differ across geographical locations, city size and income groups. In general women travel shorter distances, are more dependent on nonmotorized modes of transport and public transport. Hanson $(2010)^{3}$ concludes that the fact

1. WHO (2011), World Health Statistics, World health Organisation, Geneva

2 G Tiwari, D Jain(2012) Accessibility and safety indicators for all road users: case study Delhi BRT - Journal of Transport Geography, 2012

3 Susan Hanson(2010) Gender and Mobility: new approaches for informing sustainability, Gender, Place and Culture: A journal of Feminist Geography, 17:1, 5-23 
the women have lower mobility than men, many feminist researchers see spatial mobility as empowering and not oppressive. Lower mobility as shown by shorter distances travelled, mostly dependent on walking, and public transport is equated to lower access to employment opportunities and lower status on women. However, the understanding of sustainability will require revisiting the interpretation of lower mobility in view of the requirements of sustainable development and sustainable transport. Empowerment of women will have to come through enhanced accessibility to various opportunities without dependence on motorized mobility.

\section{SUSTAINABLE TRANSPORT: ACCESS VS MOBILITY}

Sustainable transport is often defined as one that meets the mobility needs of all users with least adverse effects on users as well as non-users. Adverse effects are in the form of poor air quality, risk of traffic crashes, lack of activity leading to obesity and other life style related diseases. Least adverse effects on users and non-users is possible when majority city residents have to travel short distances thus reducing the exposure to air pollution as well risk from traffic crashes. Short distances are conducive to travel by active (walking and bicycling) transport which is environment friendly along with giving health benefits to the users.

Walking, bicycling and public transport have least adverse effects on environment both local and global. These are also known as active transport, because the users are involved in physical activity which results in health benefits.

In the past few decades sustainable transport has become one of the main goals of transport planning and policy in many countries. Sustainable transport has also been viewed as the expression of sustainable development (Castillo and Pitfield 2010) ${ }^{4}$. There is no universally accepted definition of sustainable transport. Often sustainable transport concept has been framed by proposing principles and desirable attributes of the system. "Sustainable transport" arising from the concept of sustainable development, decouples dependence on oil; constrains GHG emissions; encapsulates having accessibility to basic daily needs consistent with human and ecosystem health; and meets affordability, equity and efficiency requirements by providing fairness across and within. (Bongardt et al. 2011; ECMT 2004; CST 2002; May et al. $2001)^{5}$ proposed five objectives for sustainable transport:

4 Castillo, H. \& Pitfield, D.E., (2010). "ELASTIC - A methodological framework for identifying and selecting sustainable transport indicators." Transportation Research Part D: Transport and Environment, 15, (4)

5 Bongardt, D., Schmid, D., Huizenga, C., \& Litman, T., (2011), "Sustainable Transport Evaluation - Developing Practical Tools for Evaluation in the Context of the CSD Process: Commission on Sustainable Development : Nineteenth Session , Background Paper No. 10." United Nation Department of Economic and Social Affairs, CSD19/2011/BP10. 
Liveable streets and neighbourhoods

i. Protection of the environment

ii. Equity and social inclusion

iii. Health and safety

iv. Support of a vibrant economy.

Protection of the environment is an important objective which includes both local environment and global environment. These can be achieved by addressing a). urban structures and land use plans which affect the distances people have to travel to access various activities, $b$ ). Modes that people chose to travel, c). Vehicle technologies and d). type of fuel used in different vehicles. Liveable streets and compact mixed use neighbourhoods allow people to make short trips. These trips can easily be made by walking and bicycles which have the least adverse impact on environment. When majority trips are by walking and bicycles, it causes least damage to the environment. Longer trips which are dependent on motorized modes cause least damage to the environment if most of it is by public transport: majority by bus and maybe some long trips by rail based systems. Lastly, trips which are made by personal motorized modes: cars and motorized two wheelers must have the smallest share, as small as possible, and the adverse impact caused by them can be minimized by efficient vehicle technology and cleaner fuels.

Distinction between the concept of Accessibility and mobility is important for sustainable and equitable transport debate. Accessibility is a description of the proximity to destinations of choice and the facilitation offered by the public transport systems to reach them (Anand, $2007)^{6}$. Accessibility as defined by Burns (1979) includes the as ability of an individual to be able to participate in an activity or set of activities (Odoki et al., 2001) ${ }^{7}$. This definition has been extended to include temporal and individual components along with spatial and transportation components (Geurs and Ritsema van Eck, 2001) ${ }^{8}$. A transport project has both

CST, (2002), "Definition and Vision of Sustainable Transportation." The Centre for Sustainable Transportation.

ECMT, (2004), "Assessment and Decision Making for Sustainable Transport." OECD Publications Service.

Feler, L. \& Henderson, J.V., (2011). "Exclusionary policies in urban development: Underservicing migrant households in Brazilian cities." Journal of Urban Economics, 69, (3) $253-272$

May, T., Jarvi-Nykanen, T., Minken, H., Ramjerdi, F., Matthews, B., \& Monzon, A., (2001), "Cities' Decision-Making Requirements: PROSPECTS Deliverable 1." Institute of Transport Studies, University of Leeds, Leeds, U.K..

6 Anand, A., 2007. Socio-Economic Impact Assessment (SEIA) Methodology for Urban Transport Projects. Indian Institute of Technology

7 Odoki, J.B., Kerali, H.R., \& Santorini, F., (2001). "An integrated model for quantifying accessibility-

benefits in developing countries." Transportation Research Part A: Policy and Practice, 35, (7), 601-623

8 Geurs, K. T. \& Ritsema van Eck, J. R., (2001), "Accessibility measures: review and applications; Evaluation of accesibility impacts of land use transport scenarios, and related social and 
positive and negative impacts on the accessibility possibilities of all road users depending on the type of mode being used. People make travel choices so that they can participate in production, consumption and leisure activities of their choice. Hence, accessibility cannot be measured just by mobility i.e. the distance travelled or by destinations in reach for a particular mode-user group.

Mobility is both the ability to travel to destinations of choice and the amount of movement necessary to do so. By definition, the ability to travel of the household is seen as positive mobility from the socio-economic perspective because indicates that people are traveling for employment, education and other purposes thus enabling value addition to the households. On the other hand the amount of movement is seen as negative mobility from the socio-economic perspective because it uses resources of the household, like time and money, which could have been better utilized to upgrade the quality of life of the household.

Women travel patterns need to be examined in the context of sustainable transport system as discussed in the previous section with an added dimension of transport-shelter-livelihood link.

\section{THE SHELTER-TRANSPORT-LIVELIHOOD LINK}

The intimate interconnections between urban transport and land-use patterns are well-known though there has been little analysis of the connections with poverty (which are somewhat complex). Common features of the land-use patterns of large low-income cities in Asia include: high urban densities (usually well above 150 persons per hectare) despite a generally low-rise built fabric; intense mixing of different land uses at a fine scale, especially in inner areas; lowincome settlements interspersed or mixed with other land-uses throughout the urban area; a high proportion of jobs (in both secondary and tertiary sectors) located in the central and inner areas of the city; however, within this inner area jobs are often relatively dispersed with no intense concentrations of employment (Barter 1998) ${ }^{9}$.

Such land-use features developed in response to the requirements of transport systems are dominated by non-motorized transport, buses, and para-transit systems. They also developed in ways that tended to minimize the need for expensive motorized travel. For example, high densities and intense mixing of land uses allow for many daily trips to be very short and thus able to be made by foot or by non-motorized vehicle. Once a city grows too large to be served primarily by non-motorized transport, a relatively centralized pattern of employment maintains a potential to support plentiful bus and jitney service (although for various reasons this potential is not always realized). Although there are some problems associated with high levels

economic impacts." National Institute of Public Health and the Environment, Netherlands, RIVM report 408505006

9 Barter, A. R. P., (1998). "Transport and Urban Poverty in Asia: A Brief Introduction to the Key Issues.". 
of crowding, such an urban form is apparently in many ways intrinsically pro-poor, in the absence of significant numbers of private cars.

However, a number of trends associated with motorization (and other factors) have begun to undermine the pro-poor features of many large Asian cities (and have created other transportrelated problems). As upper and middle-income earners have acquired private vehicles, real estate developers increasingly locate new developments to be easily accessible by private vehicle, even if this leaves them inaccessible by public transport and non-motorized transport. To the extent that high-speed, high-capacity roads have been built, they have tended to encourage haphazard development in long corridors, resulting in longer trip distances for residents of such areas. Although Asian cities have spread out to some extent as they have motorized, this is a slow process and most still retain high urban densities, especially in their inner areas. High-density cities are unsuited to high rates of private car use and inevitably have low levels of road capacity. Congestion has therefore become serious even at low levels of motorization. The rise of private vehicular traffic has decreased bus speeds and service levels drastically and made non-motorized transport dangerous and difficult. Travel for the poor has thus become slower and more difficult even as other economic and planning forces have caused many of them to be displaced from central informal settlements to more peripheral locations (Immers and Bijil 1993) ${ }^{10}$.

Many economic development programs completely miss the link between housing location, livelihoods of the poor and transport. Access to affordable transport is one of the most important factors in determining livelihoods for the urban poor. A survey by SPARC in central Bombay of pavement dwellers showed that $80 \%$ walked to work. Their choice came down to: "they were willing to live in congested dwellings without safety or security just so they could walk to work" (Gopalan 1998) ${ }^{11}$. Other studies have found similarly very limited mobility by the urban poor. Some of the urban poor have to make a different trade-off by accepting long travel distances from a peripheral location in order to obtain affordable but secure housing. For some this trade-off is forced on them, since in many cases relocation sites (after evictions) are often in remote locations that take little or no account of access issues (Fernandes 1998) ${ }^{12}$

Urban transport interacts with employment issues for the poor in two main ways: indirectly by providing access to employment opportunities and directly through employment of low-income people in the transport sector. The relative immobility of the urban poor, especially poor women is a central fact in their lives and severely limits their employment options. It has already been mentioned above that the poor must trade-off the time and cost required to access livelihood opportunities against security and quality of housing.

10 Immers, B. \& Bijil, J., (1993). "Slum Relocation and NMTs in Bangkok." Transportation Research Board, Paper \# 93CF105,

11 Gopalan, P. "Circumscribed Existence: Women's mobility and settlements development.", In SUSTRAN Network General Assembly, June 2 - 5, 1998, Manila, Mumbai: Swayam Shikshan Prayog - SSP.

Habitat, U. "Mumbai: Swayam Shikshan Prayog - SSP.", In SUSTRAN Network General Assembly - June 2 - 5, 1998.

12 Fernandes, K., (1998), "Forced Evictions and Housing Rights Abuses in Asia (Second Report 1996 - 1997)." City Press, Karachi, Pakistan. 
Understanding of gender issues in the transport context is of vital relevance. Six out of ten of the world's poorest people are women who must, as the primary family caretakers and producers of food, shoulder the burden of tilling land, grinding grain, carrying water and cooking (UNDP, 2014) ${ }^{13}$. This has marginally changed since 1995 when women were estimated to account for $70 \%$ of those living in poverty worldwide (UNDP, 1995). The growing literature on women and transport has also clearly shown that they tend to have different travel needs deriving from the multiple tasks they must perform in their households and in their communities (Greico and Turner, 1997) ${ }^{14}$. Low-income women tend also to be less mobile than men in the same socio-economic groups. They are more dependent on walking and tend to have less access to any bicycles or motorcycles in a household. Social restrictions hinder women's mobility in many cultures (Gopalan, 1998). Efforts to increase the mobility of poor women may face stiff resistance from those who feel threatened or offended by such direct empowerment of women (UNDP, 1998). Sexual harassment on streets and on public transport is also an issue. Since many more women than men are the care-givers of frail-elderly people, people with disabilities and of children, the transport problems of these disadvantaged groups also impact disproportionately on women. Poverty, of course, compounds each of these disadvantages.

Gender bias can result when there is a failure to recognize that the same service delivers different benefits to men and women. For example, the poorest households are often located on the edges of urban centres where public transport services are infrequent. In Delhi, for example, the relocation of squatter communities to the outer periphery of the city has been especially damaging to women's ability to earn a living. Female unemployment in the new squatter camps rose by $27 \%$ compared to $5 \%$ for men (Moser and Peake, 1987, cited in Alling et al 1997$)^{15}$.

\section{TRAVEL PATTERN OF WOMEN IN INDIAN CITIES}

Differences in travel patterns between men and women are different. This been reported by earlier studies from Delhi (Anand and Tiwari, 2005) ${ }^{16}$; and Chennai (Srinivasan, 2008) ${ }^{17}$. This

13 Gender and Poverty reduction, UNDP, www.undp.org

14 Grieco, M. and Turner, J. 1997, Gender Poverty and Transport, UN International Forum on Urban Poverty (HABITAT), Florence, http://www.art.man.ac.uk/transres/gender.htm

15 Alling, G., E. Brazier, D. Burjorjee, A. Camoens and A. Webber, 1997, Mainstreaming Gender in Transportation projects: A Toolkit, Report to the Gender Analysis and Policy Group, The World Bank mimeo

16 Anand, Anvita, Geetam Tiwari(2006), A gender perspective of the shelter-transport-livelihood link: the case of poor women in Delhi, Transport Reviews, Vol26,No. 1, pages 63-80 
section reports data from a smaller city compared to Delhi and Chennai-Vishakhapattnam, and revisits low income households in Delhi to understand the time trend of women travel.

Visakhapatnam is the second largest urban agglomeration in Andhra Pradesh with a population of about 1.73 million (Census, 2011). It has been and continues to be a hub of economic activity in the region, thereby leading to more and more people migrating to the city. Table 1 shows travel pattern of men and women as recorded in a recent survey ${ }^{18}$.

Table 1. Trip Purpose of Women and men in Vishakhapattanam (ITRANS, 2012)

\begin{tabular}{|l|r|r|r|r|r|r|}
\hline \multirow{2}{*}{ Purpose } & \multicolumn{2}{|c|}{ Women } & \multicolumn{2}{c|}{ men } & \multicolumn{2}{c|}{ Total } \\
\cline { 2 - 7 } & Nos. & \multicolumn{1}{c|}{$\%$} & \multicolumn{1}{c|}{ Nos. } & \multicolumn{1}{c|}{$\%$} & \multicolumn{1}{c|}{ Nos. } & \multicolumn{1}{c|}{$\%$} \\
\hline Work & 420 & $11.0 \%$ & 2868 & $62.7 \%$ & 3288 & $39.2 \%$ \\
\hline Education & 1246 & $32.7 \%$ & 1331 & $29.1 \%$ & 2577 & $30.7 \%$ \\
\hline Access to PT & 0 & $0.0 \%$ & 1 & $0.0 \%$ & 1 & $0.0 \%$ \\
\hline $\begin{array}{l}\text { Access to Auto(3 wheeler } \\
\text { taxi) }\end{array}$ & 0 & $0.0 \%$ & 0 & $0.0 \%$ & 0 & $0.0 \%$ \\
\hline Shopping & 200 & $5.2 \%$ & 105 & $2.3 \%$ & 305 & $3.6 \%$ \\
\hline Recreation & 35 & $0.9 \%$ & 34 & $0.7 \%$ & 69 & $0.8 \%$ \\
\hline Social & 6 & $0.2 \%$ & 11 & $0.2 \%$ & 17 & $0.2 \%$ \\
\hline Religious & 1880 & $49.3 \%$ & 99 & $2.2 \%$ & 1979 & $23.6 \%$ \\
\hline Personal & 18 & $0.5 \%$ & 117 & $2.6 \%$ & 135 & $1.6 \%$ \\
\hline Others & 9 & $0.2 \%$ & 8 & $0.2 \%$ & 17 & $0.2 \%$ \\
\hline Total & $\mathbf{3 8 1 4}$ & & $\mathbf{4 5 7 4}$ & & 8388 & \\
\hline
\end{tabular}

Work trips among females are less than males and religious trips (going to place of worship) is much more amongst females as compared to males. Trips made for all other purposes remains more or less the same. Table 2 shows use of different modes.

Table 2. Travel mode of Women and men in Vishakhapattanam (ITRANS, 2012)

\begin{tabular}{|l|r|r|r|r|r|r|}
\hline \multirow{2}{*}{ Mode } & \multicolumn{2}{|c|}{ Women } & \multicolumn{2}{c|}{ Men } & \multicolumn{2}{c|}{ Total } \\
\cline { 2 - 7 } & \multicolumn{1}{|c|}{ Nos. } & \multicolumn{1}{c|}{$\%$} & \multicolumn{1}{c|}{ Nos. } & \multicolumn{1}{c|}{$\%$} & \multicolumn{1}{c|}{ Nos. } & \multicolumn{1}{c|}{$\%$} \\
\hline Car & 31 & $0.8 \%$ & 97 & $2.1 \%$ & 128 & $1.5 \%$ \\
\hline M2W & 195 & $5.1 \%$ & 1061 & $23.2 \%$ & 1256 & $15.0 \%$ \\
\hline Bus & 482 & $12.6 \%$ & 968 & $21.2 \%$ & 1450 & $17.3 \%$ \\
\hline Auto - Direct & 205 & $5.4 \%$ & 293 & $6.4 \%$ & 498 & $5.9 \%$ \\
\hline
\end{tabular}

17 Srinivasan, S.(2008), A partial exploration of the accessibility of low-income women: Chengdu, China and Chennai, India in Gendered mobilities, ed. T. Cresswell and T.P. Uteng, 143-58, Burlington, VT, Ashgate Publishing Co. 


\begin{tabular}{|l|r|r|r|r|r|r|} 
Auto -Shared & 114 & $3.0 \%$ & 175 & $3.8 \%$ & 289 & $3.4 \%$ \\
\hline Walk & 2711 & $71.1 \%$ & 1616 & $35.3 \%$ & 4327 & $51.6 \%$ \\
\hline Bicycle & 29 & $0.8 \%$ & 265 & $5.8 \%$ & 294 & $3.5 \%$ \\
\hline Cycle-Rickshaw & 1 & $0.0 \%$ & 10 & $0.2 \%$ & 11 & $0.1 \%$ \\
\hline Company Bus & 33 & $0.9 \%$ & 49 & $1.1 \%$ & 82 & $1.0 \%$ \\
\hline Taxi & 2 & $0.1 \%$ & 1 & $0.0 \%$ & 3 & $0.0 \%$ \\
\hline Others & 9 & $0.2 \%$ & 37 & $0.8 \%$ & 46 & $0.5 \%$ \\
\hline Total & $\mathbf{3 8 1 2}$ & & $\mathbf{4 5 7 2}$ & & $\mathbf{8 3 8 4}$ & \\
\hline
\end{tabular}

Walking has the highest share of trips; however, this is much more the case for women than men. The use of motorized two wheeler and bus transport is more marked for men.

Tables 3 and 4 show trip distance and trip time. Women travel shorter distances, however travel time is similar, showing dependence of women on non-motorized slower modes of transport.

Table 3. Trip length (km) of Women and men in Vishakhapattanam (ITRANS, 2012)

\begin{tabular}{|l|r|r|r|r|r|r|}
\hline \multirow{2}{*}{ Distance (km.) } & \multicolumn{2}{|c|}{ Women } & \multicolumn{2}{c|}{ Men } & \multicolumn{2}{c|}{ Total } \\
\cline { 2 - 7 } & \multicolumn{1}{|c|}{ Nos. } & \multicolumn{1}{c|}{$\%$} & \multicolumn{1}{c|}{ Nos. } & \multicolumn{1}{c|}{$\%$} & \multicolumn{1}{c|}{ Nos. } & \multicolumn{1}{c|}{$\%$} \\
\hline$<\mathbf{1}$ & 2678 & $70.6 \%$ & 1810 & $39.7 \%$ & 4488 & $53.7 \%$ \\
\hline $\mathbf{1 - 3}$ & 510 & $13.4 \%$ & 1010 & $22.1 \%$ & 1520 & $18.2 \%$ \\
\hline $\mathbf{3 - 5}$ & 223 & $5.9 \%$ & 545 & $12.0 \%$ & 768 & $9.2 \%$ \\
\hline $\mathbf{5 - 1 0}$ & 222 & $5.8 \%$ & 656 & $14.4 \%$ & 878 & $10.5 \%$ \\
\hline$>\mathbf{1 0}$ & 162 & $4.3 \%$ & 539 & $11.8 \%$ & 701 & $8.4 \%$ \\
\hline Total & $\mathbf{3 7 9 5}$ & & $\mathbf{4 5 6 0}$ & & $\mathbf{8 3 5 5}$ & \\
\hline
\end{tabular}

Table 4. Trip Time of Women and men in Vishakhapattanam (ITRANS, 2012)

\begin{tabular}{|l|r|r|r|r|r|r|}
\hline \multirow{2}{*}{ Time (mins.) } & \multicolumn{2}{|c|}{ Women } & \multicolumn{2}{c|}{ Men } & \multicolumn{2}{c|}{ Total } \\
\cline { 2 - 7 } & \multicolumn{1}{|c|}{ Nos. } & \multicolumn{1}{c|}{$\%$} & \multicolumn{1}{c|}{ Nos. } & \multicolumn{1}{c|}{$\%$} & \multicolumn{1}{c|}{ Nos. } & \multicolumn{1}{c|}{$\%$} \\
\hline $\mathbf{2 1 0}$ & 1767 & $46.3 \%$ & 1146 & $25.1 \%$ & 2913 & $34.7 \%$ \\
\hline $\mathbf{1 0 - 2 0}$ & 1180 & $30.9 \%$ & 1488 & $32.5 \%$ & 2668 & $31.8 \%$ \\
\hline $\mathbf{2 0 - 3 0}$ & 404 & $10.6 \%$ & 874 & $19.1 \%$ & 1278 & $15.2 \%$ \\
\hline $\mathbf{3 0 - 5 0}$ & 306 & $8.0 \%$ & 595 & $13.0 \%$ & 901 & $10.7 \%$ \\
\hline $\mathbf{5 0 - 7 0}$ & 103 & $2.7 \%$ & 289 & $6.3 \%$ & 392 & $4.7 \%$ \\
\hline$>\mathbf{7 0}$ & 54 & $1.4 \%$ & 182 & $4.0 \%$ & 236 & $2.8 \%$ \\
\hline Total & $\mathbf{3 8 1 4}$ & & $\mathbf{4 5 7 4}$ & & $\mathbf{8 3 8 8}$ & \\
\hline
\end{tabular}


Figure 1 and 2 show trip purpose and travel mode used by income groups.

Figure 1. Trip purpose of Women and Men in different income groups

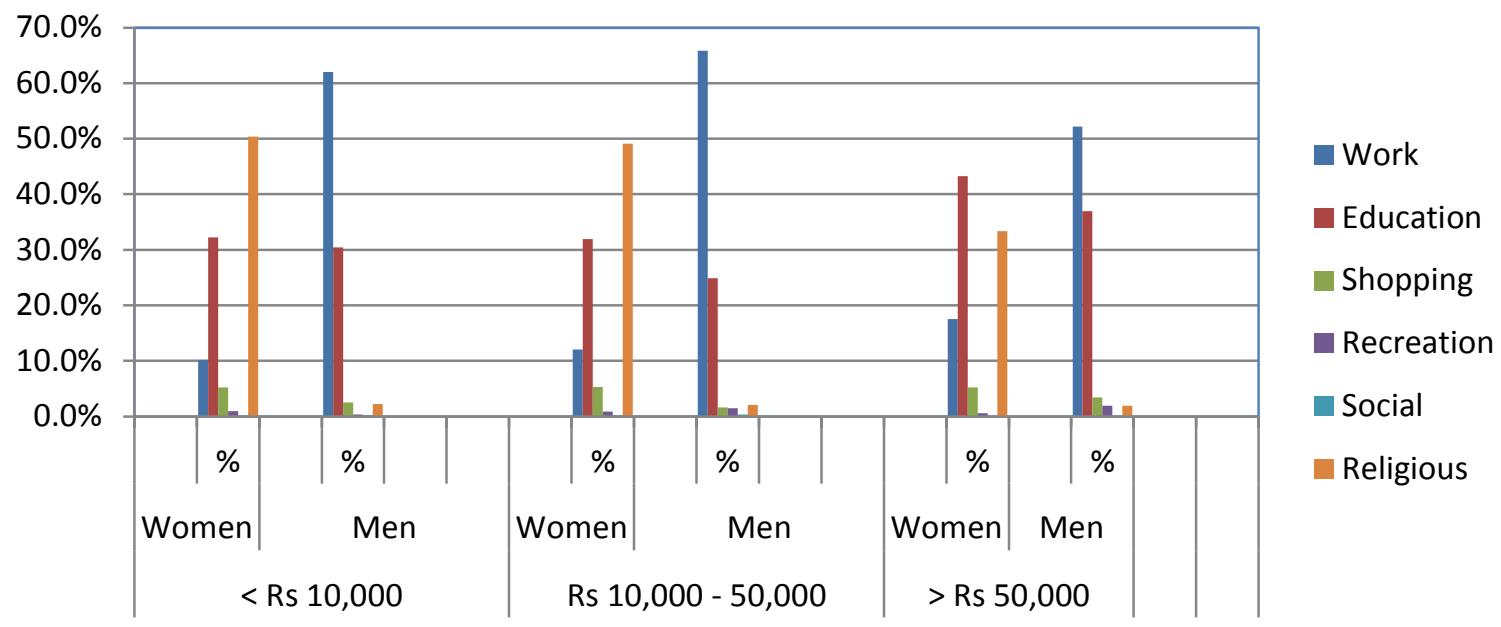

Figure 2. Travel Mode of Women and Men in Different income groups

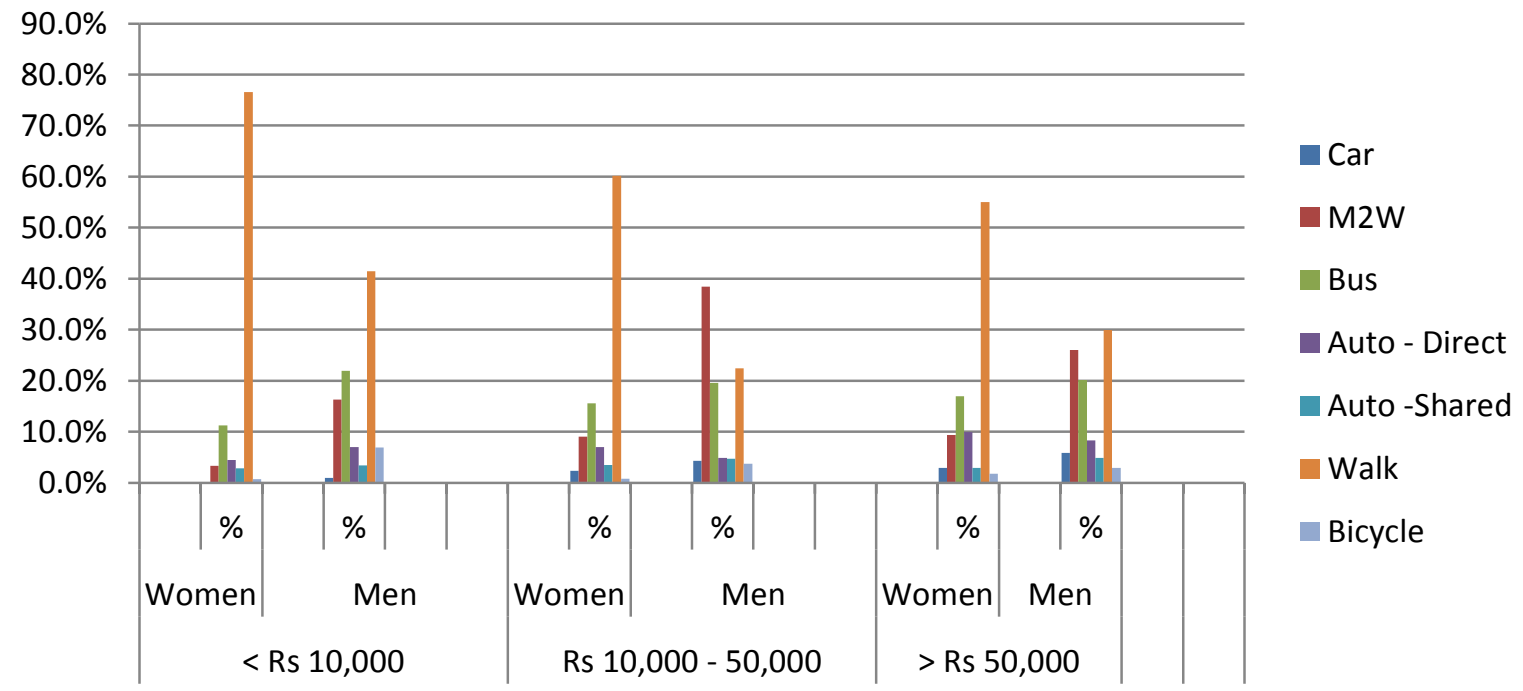

With increase in income share of work trips increase in women, however it remains lower than men. Share of religious trips seems to decrease amongst women with increase in income. Figure 2 shows dominance of walk trips amongst women as compared to men, however with increase in income this gap seems to reduce. Similarly with increase in come, gap in public transport trips amongst women and men seem to be narrowing, higher income men and women have similar share of trips on public transport. Bicycle users are more amongst men as compared to women. 
These trends are similar to reported by earlier authors showing $83 \%$ women trips were walking trips and $63 \%$ men trips were walking trips in Chennai, India. ( Srinivasan, $2008^{19}$ ). Anand and Tiwari (2006) reported similar trends observed in Delhi in 2001 of low income households. Women either walk to work or use public transport. Share of women walking to work is much higher (52\%) than men(26\%).

A follow up survey(TRIPP, 2012) done in Delhi of low income households shows more women employed in informal employment as compared to men( $86 \%$ vs $74 \%)$. Amongst employed persons, women are more dependent on walking as compared to employed men. Use of bicycle is negligible amongst women, and bus use is much less than men. Differences in travel trends observed in 2001 remain unchanged after ten years.

Table 5. Travel mode used by employed men and women

(Low income households in Delhi, 2012)

\begin{tabular}{|l|l|l|l|l|}
\hline Mode of Travel & Employed Persons & Unemployed persons & Employed Men & Employed Women \\
\hline Walk & $49 \%$ & $87 \%$ & $34 \%$ & $86 \%$ \\
\hline Bicycle & $15 \%$ & $2 \%$ & $22 \%$ & $1 \%$ \\
\hline Bus & $23 \%$ & $8 \%$ & $27 \%$ & $13 \%$ \\
\hline
\end{tabular}

Two important conclusions emerge from this data. Women are dependent on walking regardless of income differentiation. There is a significant difference in distances travelled by women and men, however, travel time is similar, implying that men have higher spatial accessibility. Lower use of bicycles and public transport has been observed earlier (Anand and Tiwari, 2006). In lower income groups, women may have lower access to bicycle both due to lower ownership of vehicles as well as inequality amongst men and women in households. Men have the 'first right' over the vehicle owned by households. Lower use of public transport by low income women is also due to cost implications of public transport. A subsidized public transport also remains prohibitively expensive to a significant proportion of the population $(\text { Tiwari,2002) })^{20}$.

For a shortest trip by bus in Delhi the monthly expenditure would be at least Rs. 600 per person. If two persons travel in a household, this would require a monthly income of about Rs.12000-15000 assuming at least 10\% income will be spent on transport needs.

19 Srinivasan, S, 2008, A spatial exploration of the accessibility of low income women: Chengdu , China and Chennai, India. In Gendered mobilities, ed T. Cresswell and T.P. Uteng, 143-58

20 Tiwari, G., (2002). "Urban Transport Priorities: Meeting the Challenge of Socio-economic Diversity in Cities, a Case Study of Delhi, India." Cities, 19, (2) 95-103 


\section{SAFETY PERCEPTIONS OF BICYCLE, PEDESTRIANS AND PUBLIC TRANSPORT USERS}

Lower use of bicycle and public transport is observed in middle income and high income households also. Lack of safe infrastructure and fear from crime has been reported as one of the most important reasons for not using bicycles for short trips (Jain and Tiwari,2011) ${ }^{21}$. This study reported survey of current bicyclists and potential bicyclist in Pune, India. Most cyclists in Indian cities are not using bicycles by choice. However, there is a huge potential of cycle trips due to presence of short trips and high ownership of bicycles amongst middle and high income households in Indian cities. The survey targeted current cyclists (captive cyclists) and potential cyclists both. The current captive cyclists and potential cyclists, both attach higher scores/ranks (consider it most important or important) to physical safety (up to $75 \%$ in captives and $82 \%$ in potential cyclists). This is closely followed by the social security (62\% in captive users and $58 \%$ in potential users). Twenty eight percent of captive and potential cyclists consider conditions at intersections as barrier to cycling. Preferences of women and men for bicycle routes show similar trends except a few variables. Women attach lower weights to intersections and other barriers as compared to men. Women also gave higher weight to social security aspects, informal land use presence and formal land use mix. This further emphasizes the importance of social security for women.

Figure 3. Ranking of variables for safe bicycle route by women and men (Jain, 2011)

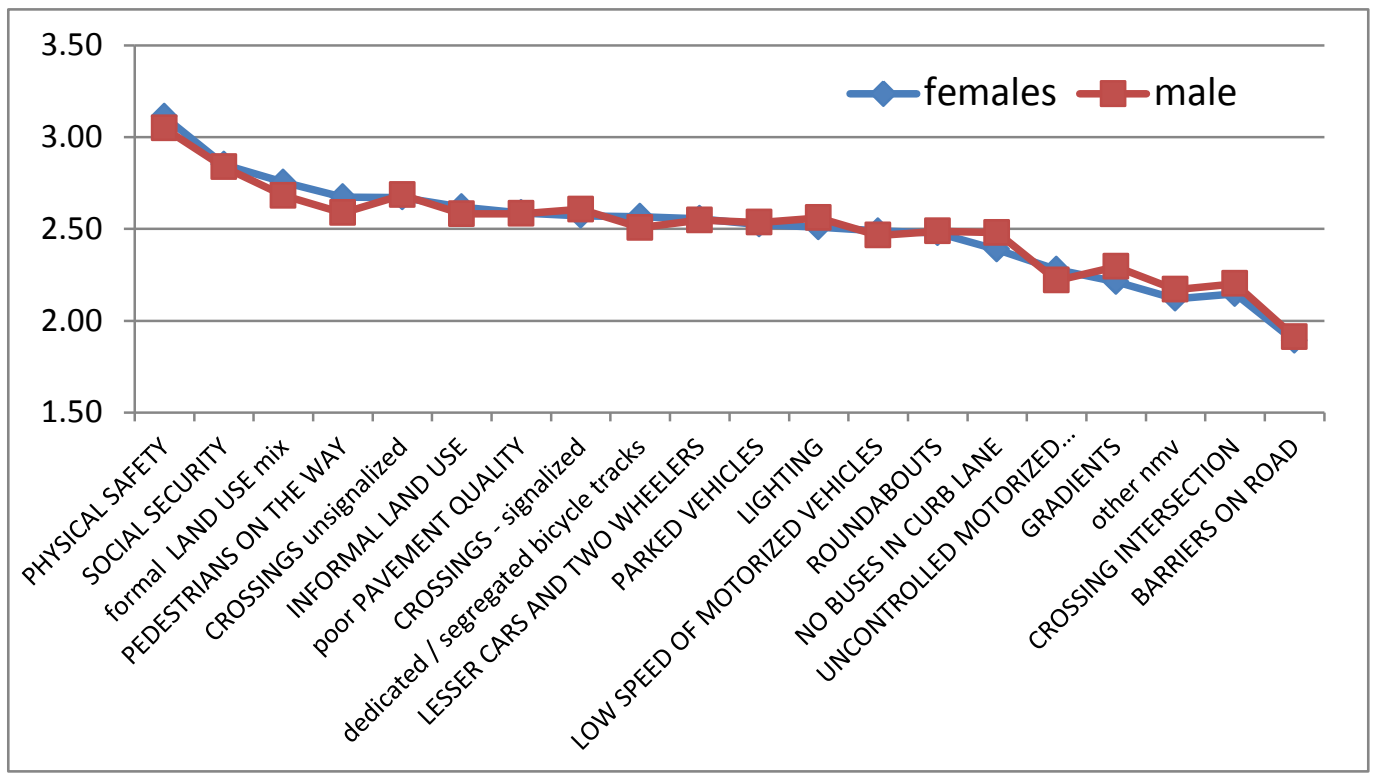

21 Jain Himani and Geetam Tiwari(2011), Captive cyclists vs potential users: Route chice factrs in Indian Context, TRIPP research Report, IIT Delhi 
Perception of high risk from traffic crashes as pedestrian, bicycle user and public transport commuters has been reported by other researchers from other Indian cities as well (Rankawat and Tiwari,2013) ${ }^{22}$. Rankawat et al. reported the results of pedestrian preferences about the pedestrian facilities, across and along the road, in Delhi, India to understand how built environment could be improved to facilitate pedestrian movement. The study showed that usage of subways is less by female respondents, zebra crossing is convenient in usage but not safe and usage of the footpaths can be increased by increasing safety. The study also showed that the majority of the people do not find it safe to walk in Delhi with the present state of street lighting. Women and men again showed different trends in using different facilities. The study reported that there was less use of subways by female respondents as compared to their male counterparts and use of subways was positively related with convenience perception. As the pedestrians perceived subways as more and more convenient, they tend to use it more. Cheung and Lam $(1998)^{23}$ also found that pedestrians prefer escalators to stairways. Age, gender and convenience perceptions are statistically significant for the use of zebra crossing, while safety perception is not statistically significant. Use of zebra crossings was preferred by women.

Convenience perception is statistically significant for the use of foot over bridge (FOB). Gender parameter is approximately $83 \%$ significant, implying that there was less use of foot over bridge by female respondents as compared to their male counterparts. These findings can be used to redesign safe pedestrian crossing facilities for all in cities.

\section{IMPACT OF CURRENT PLANNING PRACTICES AND URBAN ROAD DESIGNS}

Resettlement Policies of low income residents have led to lower access to employment opportunities for all but more for women. Most of urban landuse policies have not been very effective in addressing the needs of poor households who locate close to employment opportunities in the city, often squatting on the land not designated for residential use as per the master plan. However, this location results in short travel distances for pedestrians and bicyclists.

\section{Urban planning and Safety}

City planning policies which include the location of different activities, location of residential areas and planning of transport networks influence the choice of transport modes as well as distances that various people have to travel. Thus exposure to road traffic risk is influenced by the planning policies at city level. Mixed land use patterns reduce the length of trips and thus exposure to road traffic injuries. Often poor households are relocated at the outskirts of the city limits where land is cheap. This results in long pedestrian and bicycle trips increasing exposure to road traffic crashes. Thus road traffic risk to different road users is influenced by the city planning policies.

22 Rankawat, Shalini; Tiwari, Geetam, and Single, Nikita (2013), Analysis of Pedestrian Perception towards Pedestrian facilities, TRIPP Research Report, IIT Delhi

23 Cheung, C.Y., Lam, W.H.K., 1998. Pedestrian route choices between escalators and stairways in metro stations. J. Transport. Eng. 124, 277-285. 
Anand (2007) ${ }^{24}$ showed, for poor households relocated to new areas in Delhi to make space for metro construction in Delhi, there was a significant impact on the indicators of accessibility and mobility. The land-use accessibility deteriorated as distance to education, health services and other urban services increased for $52 \%, 63 \%$ and $52 \%$ of the households respectively. The transport accessibility deteriorated even more as distance to bus stop increased for $72 \%$ of the households and the bus frequency decreased, on an average, from $5 \mathrm{~min}$ to $63 \mathrm{~min}$ (almost 13 times). The mobility of the households increased significantly. The per capita trip rate for work increased for $49 \%$ of the households and decreased for $30 \%$, implying change in the number of trips made for work in the households. The share of bicycles used decreased for $59 \%$ of the households. The mobility indicators for travel to work - distance, time and cost -increased for $83 \%$, $82 \%$ and $61 \%$ of the households respectively.

The case study from Delhi shows how the land use policies supporting the official Delhi Master plan result in relocating poor households to the outskirts of the city to accommodate transport infrastructure like road expansion or the metro. This has resulted in increased travel distances and travel time for most households. The longer walking and bicycle trips on roads without any dedicated facilities for theses modes increase the risk of getting involved in a fatal crash. The current relocation policies increase the vulnerability of the current vulnerable road users. The land use policies must ensure that especially the poor households, who cannot afford any form of motorized travel, are located close to employment opportunities resulting in short travel distances. This will result in reducing the risk of fatal crashes because the distances and travel time will reduce in addition to increasing the accessibility to education, health facilities and employment opportunities.

\section{URBAN ROAD DESIGN AND SAFETY}

At design level, design of road infrastructure (road cross section, carriageway width, intersection design), facilities for pedestrians, bicycles and public transport users influence the risk taking behaviour of road users. This includes observance of speed limits by car and bus drivers, waiting for sufficient gaps by pedestrians and use of zebra crossings and pedestrian subways. A study (Gupta et al., 2010) ${ }^{25}$ was carried out at the AIIMS flyover interchange in New Delhi. This intersection carries large flows of bus, pedestrian, and motor traffic. The Ring Road, which is a major arterial road, and Aurobindo Marg forms the AIIMS grade-separated interchange. Traffic data collection allowed the study of road user behaviour earlier when the AIIMS junction was an atgrade, signalized intersection and presently when the site is a grade separated interchange with no traffic signal control. Analysis produced results pertaining to

24 Anand, A., 2007. Socio-Economic Impact Assessment (SEIA) Methodology for Urban Transport Projects. Indian Institute of Technology. Behaviour and Survival Analysis, Journal of the Eastern Asia Society for Transportation Studies, Vol.8, 2010 
pedestrian crossing behaviour as a function of observable pedestrian, environment, and traffic characteristics.

The study showed that higher percentages of vehicles are traveling with higher speeds in all categories after reconstruction. Risk to pedestrians has increased because conflicting vehicle speeds after reconstruction are higher as compared to before reconstruction.

For those pedestrians who crossed at risk, average accepted gap decreased in the after reconstruction case. They accepted greater risk in each stage of crossing primarily because of the higher average speeds of the vehicle groups. The speeds increased $21.6 \%, 22.6 \%, 15 \%, 31.6 \%$ for the heavy vehicle, car, motorized three-wheeler, and motorized two wheeler groups, respectively. The probability of pedestrian fatality with a specific vehicle group increase 67 percent, 100 percent, 100 percent, and 200 percent, respectively.

Twenty two percent of pedestrians accepted increased risk despite the presence of a nearby pedestrian underpass. The study concluded that after the construction of grade separated junction risk to pedestrians increased substantially both because of higher speeds of motorized vehicles and because of accepting shorter gaps by pedestrians for road crossing.

The conventional understanding of measuring performance of a transport infrastructure is biased towards the car traffic. Level of service of an intersection is measured in terms of delay faced by the motorized traffic. Therefore delays faced by motorized traffic at intersections have become a major source of concern for planners, traffic policy and road owning agencies. Road expansion schemes and signal free junctions have become synonymous with "improvement" of transport infrastructure. Since problems faced by pedestrians and bicyclists, the two most vulnerable road users are not viewed as major transport issues, the "improvement" strategies do not take into account impacts on pedestrian movements. The conversion of signalized junction at AIIMS in Delhi to signal free junction has resulted in increase in motorized traffic and increase in risk faced by pedestrians while crossing the road. However, when road designs include the needs of pedestrians, bicyclists and public transport vehicles as the Delhi BRT case study presented, number of crashes can be reduced ${ }^{26}$.

\section{WHAT CAN BE DONE?}

Women have different travel patterns is universally observed and has been reported several times in the last three decades. The travel choice is embedded in several social context and complex relationships in the society (Hanson, 2010). The debate on sustainability has added another dimension to mobility poverty of women. The sustainability concern requires changing the focus from mobility and enhancing

26 Tiwari, G. \& Jain, D. (2012) Accessibility and safety indicators for all road users: case study Delhi BRT. Journal of Transport Geography, 22 ,87-95 
accessibility with less dependence on motorized modes especially private cars. An important change required at all level of interventions is to accept women centric planning and design as the minimum requirement for inclusive and sustainable development. As argued by Murthy (2011) ${ }^{27}$, Urban form and transport needs must be recast based on collective aspirations for public space. In the case of developing countries like India, enhanced accessibility must ensure safe pedestrian and bicycle access to various opportunities. Therefore, planning and designing safe transport systems for women requires intervention at three levels:

- Land use planning

- Street designs

- Public transport infrastructure

Urban planning policies and land use policies decide the location of different activities and location of residential areas. Most of these policies have not been very effective in addressing the needs of poor households who locate close to employment opportunities in the city often squatting on the land not designated for residential use as per the master plan. However, this location results in short travel distances for pedestrians and bicyclists. This also provides more employment The case study from Delhi shows how the land use policies supporting the official master plan result in relocating poor households at the outskirts of the city to accommodate transport infrastructure like road expansion or metro. This has resulted in increasing travel distances and travel time for most households. The longer walking and bicycle trips on roads without any dedicated facilities for theses modes increase the risk of getting involved fatal crash. The current relocation policies increase the vulnerability of the current vulnerable road users. If the land use policies ensure that especially the poor households who cannot afford any form of motorized travel are located close to employment opportunities resulting in short travel distances. This will result in reducing the risk of fatal crashes because the distances and travel time will reduce in addition to increasing the accessibility to education, health facilities and employment opportunities.

Street Designs: The conventional understanding of measuring performance of a transport infrastructure is biased towards the car traffic. Level of service of an intersection is measured in terms of delay faced by the motorized traffic. Therefore delays faced by motorized traffic at intersections have become a major source of concern for planners, traffic policy and road owning agencies. Road expansion schemes and signal free junctions have become synonymous with "improvement" of transport infrastructure. Since problems faced by pedestrians and bicyclists, the two most vulnerable road users are not viewed as major transport issues, the "improvement" strategies do not take into account impacts on pedestrian movements.

Improving pedestrian safety requires making pedestrian safety audits and pedestrian compliant designs mandatory in cities. While improved geometric standards and operational measures will have an impact on physical safety, policies of encouraging

27 Murthy, Kavya, (2011), Urban Transport and the right to the city, accessibility and mobility in Marie-Helene Zerah, Veronique Dupont and Stephanie Tawa Lama Rewal (eds), Urban Policies and the Right to the City in India: Rights, Responsibilities and Citizenship, UNESCO, INDIA and $\mathrm{CSH}$, India, pages 122-132 
presence of street vendors and activity along the travel corridor will ensure social security.

Public transport infrastructure: Design of public transport infrastructure which includes access to public transport stops, the design of the stop, vehicle design will have to become safety and security compliant. Cardia (2012) has given a list of policy interventions required to improve public transport safety for all. These are:

Public transport safety must be guaranteed during the whole length of the trip: on vehicles, during the waiting time, and on the routes of access to stations and stops. Every access should be checked and improved.

Old people and women are particularly sensitive to the problems of personal safety on public transport networks. Increasingly frequent action is required by the operators.

The need of taking immediate action requires a direct connection between staff, the operational centre and the police.

Lighting, good design, visibility at stops and stations are an essential component in creating feelings of security.

In transportation planning, of course there needs to be a hierarchy with pedestrians and cyclists (the most vulnerable group) at the top and car users at the bottom. Instead of trend projections from the past, we have to depend on scenario building techniques- for instance, transport planners need to have a city vision; they need to think about how the quality of life in a city would be affected by a particular choice in transport. The choices made will go a long way in determining people's behaviour and lifestyles. To do this, planners will need to assess the impact their decisions will make on safety, socioeconomic benefits to different users groups and environmental aspects. 
